\title{
A concepção de "movimento" em Lettres portugaises. Novo momento na representação da subjetividade ocidental
}

\author{
André Luiz Barros
}

No século XVII francês, a palavra "mouvement" [movimento] tem um significado mais amplo e menos mecanicista do que o que lhe atribuímos hoje: retrata variações da "alma" ou das "coisas morais" ${ }^{1}$, cujo desenrolar a prosa de ficção tomará para si a tarefa de descrever. A análise do sentido dessa palavra no romance Lettres portugaises, lançado em 1669, e somente três séculos depois atribuído a Guillerages², nos permitirá descrever um momento de transição particularmente importante na forma de representar a subjetividade amorosa na prosa de ficção. Trata-se de demonstrar como se dá a mudança em relação a uma concepção clássica das belles-lettres, que excluía a representação mais realista dos impulsos amorosos ${ }^{3}$. Pretendemos examinar o texto de 1669, supondo ver nele um novo tipo de representação ficcional em prosa, que inclui uma dimensão íntima do personagem. O tex to é um importante ancestral do romance epistolar do século XVIII, gênero que prescinde não apenas do decoro (bienséance) constitutivo de uma poética clássica, mas também da concepção de obra como lugar de um afastamento regrado em relação à vida cotidiana. Ao passo que, no nível mimético, há o estabelecimento desse novo patamar realista, ainda pouco prestigiado pelo gosto dominante, o romance de Guillerages é também privilegiado por permitir analisar a semântica não só de mouvement, como também de um termo dele derivado, émo-

\footnotetext{
${ }^{1}$ Ver o início do item 1.

${ }^{2}$ Mais especificamente, em 1962, por Frédéric Deloffre. Cf. Guillerages. Lettres portugaises (1669). Paris: Gallimard, 1990.

${ }^{3}$ Aqui, o termo "realista" se refere não ao estilo surgido em meados do século XIX, com Balzac e Stendhal, que acabaria desembocando no naturalismo, mas a uma forma de representação mais concreta do cotidiano, no sentido de Auerbach (no caso, "mais concreta" quer dizer "incluindo o baixo corporal", algo que ia contra os preceitos do classicismo). Cf. Auerbach, Erich. Mímesis: a representação da realidade na literatura ocidental (1946). São Paulo: Perspectiva, 1994.
} 
" (Dictionnaire de l'Aca démie françoise, dédié au Roy. Tome Second. Paris: Jean-Baptiste Coignard 1694: 97). tion, de uso ainda pouco comum, na época. Tal semântica será responsável pela melhor conformação de um ethos subjetivo específico, alternando liberação e contenção sentimentais, em contraponto à valorização unilateral clássica das passions, por exemplo, em Corneille e Racine. Tal alternância, marcada pela defesa que Mariane, a protagonista do romance, faz do combate contra o transbordamento amoroso, representa um momento particularmente rico de instauração do modo narrativo das emoções, em um panorama cultural que sofre uma visível transformação a partir do classicismo.

\section{Sentidos dicionarizados de uma palavra}

Na primeira edição do Dictionnaire de l'Académie françoise, de 1694, lê-se que o verbo "mouvoir” possui, além do significado trivial de "remuer" (mexer), sinônimo de "faire aller d'un lieu à un autre" [fazer ir de um lugar a outro], outro mais abstrato: "Il se dit aussi des facultez de l'ame, \& des choses Morales, \& signifie, exciter, donner quelque impulsion, faire agir" [Diz-se também das faculdades da alma e das coisas morais, e significa excitar, dar algum impulso, fazer agir $]^{*_{4}}$. Percebe-se, já aí, a força do termo no que toca à variação de estados emocionais. De princípio, destaquemos que o uso da expressão "estados emocionais" ou, numa variação, "estados subjetivos” constitui anacronismo terminológico: fica claro que falamos para um leitor pós-século XVIII. No próprio trecho citado, encontramse as expressões usadas na época: "facultez de l'ame” e "choses Morales".

A localização na alma e na moralidade aponta para uma ancestral divisão do domínio que hoje se denominaria "emocional" ou "subjetivo": por um lado, o termo "alma” pertence ao território aristotélico, apropriado pelo discurso eclesiástico; por outro, "coisas morais" tem a ver com o discurso sobre os atos humanos, ou seja, sobre o homem (o humanismo em sua versão seiscentista). Em texto de 1941, Erich Auerbach empreende uma interessante história do termo “paixão”, que acaba tomando a forma de uma verdadeira genealogia cultural de tal divisão. $\mathrm{O}$ crítico alemão defende uma origem greco-romana da palavra pathos (em latim, passio), ligada, de um lado, a Aristóteles e, de outro, ao estoicismo. No primeiro caso, trata-se de passio no sentido de doença ou (diríamos nós) de emoção

\footnotetext{
${ }^{4}$ Nas citações de verbetes dos dicionários, mantenho a grafia da época.
} 
forte que se sofre, cuja tônica é a passividade. No segundo caso, há uma dimensão pejorativa na passio como oposição à ratio, ou seja, à razão: a passio é algo que se deve evitar ou controlar no comportamento do homem, pois vai contra a racionalidade e seu salutar domínio sobre a vida e sobre si mesmo* ${ }^{*}$.

Essa dupla origem semântica do termo, anterior à sua acepção pós-séculos XVII e XVIII, aponta para a ancestralidade de nosso termo "emoção". Na verdade, como veremos no item 3, émotion deriva de mouvement, o que, a princípio, já nos situa na esfera semântica dos estados subjetivos, na forma como eram nomeados na literatura do século XVIII francês. Comecemos por mouvement, para só depois chegar ao desenvolvimento em émotion. Na mesma edição do Dictionnaire de l'Académie, lê-se que, em "Dogmática”, “Mouvement d'alteration” significa "Le changement qui arrive dans un corps par le mouvement insensible de ses parties" [A mudança que acontece a um corpo pelo movimento insensível (não perceptível) de suas partes]". Também de um homem dado a "intrigues" [intrigas] - no caso, certamente intrigas de corte -, diz-se que é "un homme qui se donne bien du mouvement" [um homem que faz bastante movimento]. Finalmente, "Il se dit aussi des differentes impulsions, passions, ou affections de l'ame” [Diz-se também dos diferentes impulsos, paixões ou afecções da alma]. Os exemplos que se seguem são, para nós, esclarecedores:

Movimento voluntário. Movimento involuntário. [...] Não se é mestre dos primeiros movimentos. [...] A vontade movimenta as outras faculdades. Ele fez isso por um bom movimento [...] ele não fez isso [...] de movimento próprio [...]. Excitar, acalmar os movimentos da alma.
Mouvement volontaire. mouvement involontaire. [...] on n'est pas maistre des premiers mouvements. [...] la volonté donne le mouvement aux autres facultez. Il a fait cela par un bon mouvement $[\ldots]$ il n'a pas fait cela $[. .$.$] de son propre$ mouvement [...]. exciter, calmer les mouvements de l'ame.*
" (Auerbach, Erich. "De la Passio aux passions". Em: Le culte des passions Essais sur le XVIlè siècle Français. Paris: Macula, 1998: 54-6).

"(Dictionnaire de l'Académie françoise, dédié au Roy. Tome Second. Ob. cit.: 98).

"Auerbach ressalta que, "na Antigüidade, os campos semânticos decerto são separados de forma diferente, mas [...] os conteúdos psicológicos estão todos presentes lá, e são desenvolvidos com uma grande precisão”, o que parece nos autorizar a perceber na passio greco-romana o germe da idéia de inconstância emocional subjacente ao termo mouvement na França do século XVII. Cf. Auerbach, Erich "De la Passio aux passions". Ob cit.: 53. 
* "Mouvant: Qui a la puis. sance de mouvoir. [...] Force mouvante, qui se dit de l'instrument mechanique, par le moyen duque on donne une plus grande impression de mouvement aux choses qu'on veut remuer" ( : 98).

Como se vê, estamos em pleno território de uma semântica do dinamismo dos impulsos, das afecções, das paixões, três termos definitivamente não anacrônicos em relação à época examinada. Os exemplos são ricos porque apontam para uma figuração da mecânica de tais impulsos, e sugerem a complexidade do uso do termo na época: há tanto voluntarismo (ou seja, tradução em atos de uma vontade, retratada como o dínamo das demais faculdades) quanto movimento involuntário, do qual não se é "mestre". No limite, mouvement chega mesmo a substituir o termo "vontade", dificultando uma tradução atual: "Il n'a pas fait cela $[\ldots .$.$] de son propre mouvement" ["ele não o fez [\ldots]$ de seu próprio movimento"], hoje facilmente substituível por "de sua própria vontade”. Quanto ao termo “mecânica”, por nós usado, alude a um significado de mouvement que a modernidade, sabidamente técnica e mecanicista, consagraria, mas que já se observava, na época: "Movente (ou Móvel): que tem o poder de mover. [...] Força movente, que se diz do instrumento mecânico por meio do qual se faz aumentar a impressão de movimento às coisas que se quer mudar de lugar"*.

O significado imediato de hoje se localiza no pólo oposto da acepção mais abstrata, mais ligada aos afetos ou, para sermos seiscentistas, mais "sensível”. Daí que, num exercício livre de imaginação, preferiríamos usar hoje "impulsos”, "inquietudes”, “angústias”, “calores”, cujo ancestral seiscentista é "vapeurs”, "vapores” etc., a fim de aludir ao que um francês do século XVII queria dizer com mouvements. Mas o campo de significação da palavra não termina aí. Um exame mais detido da incidência do termo em Lettres portugaises deve nos levar a melhor circunscrever sua riqueza de sentidos.

\section{Lettres portugaises: saga de uma palavra e de uma concepção da vida interior}

Já na primeira das cinco cartas de Lettres portugaises se acha um exemplo do uso de mouvement que relaciona a palavra a um órgão do corpo que sabidamente terá destino especial no século XVIII, rumo ao romantismo:

Como pode ser que as recordações de momentos tão agradáveis tenham se tornado tão cruéis? E é necessário que, contra a natureza deles, não sirvam senão para tiranizar meu coração? Ora!
Comment peut-il faire que les souvenirs des moments si agréables soient devenus si cruels? et faut-il que, contre leur nature, ils ne servent qu'à tyranniser mon coeur? Hélas! 
Vossa última carta reduziu-o a um estranho estado: ele expressou movimentos tão sensíveis de modo a, pelo que parece, fazer esforços para se separar de mim, e para ir vos buscar, eu fiquei tão abatida com todas essas emoções violentas, que fiquei mais de três horas abandonada de todos os meus sentidos...6
Votre dernière lettre le réduisit en un étrange état: il eut des mouvements si sensibles, qu'il fit, ce semble, des efforts pour se séparer de moi, et pour vous aller trouver; je fus si accablée de toutes ces émotions violentes, que je demeurai plus de trois heures abandonnée de tous mes sens...*
"(Guillerages. Lettres portugaises. Ob. cit.: 76).

A passagem, na verdade, parece extraída de algum autor do alto romantismo, na linhagem de Rousseau: o coração sofre (no sentido aristotélico de pathos, paixão) movimentos sensíveis, que, como dínamos, levam-no quase a separar-se do corpo da protagonista e ir à procura de seu amante. Trechos como esse, no entanto, enganam no caso do romance atribuído a Guillerages, pois se a narrativa de Lettres portugaises pode, de fato, ser vista como ancestral do discurso romântico do transbordamento amoroso "do coração", a verdade é que ela não partilha da semântica estrita de tal movimento, que só desabrochou na Alemanha em fins do século XVIII. Tal constatação vem do fato de a freira Mariane, a protagonista, manter uma postura típica do Ancien Régime, no sentido de nunca culpar o oficial francês e sequer cogitar reivindicar seus direitos, nem um novo ethos para a mulher não aristocrata. Concordamos com Frédéric Deloffre, quando ele destaca em sua introdução ao Dicionário:

Mariane não tem nada de "bela alma" à maneira de La Nouvelle Helö̈se Na história das mentalidades, a originalidade maior da obra é a de retratar uma paixão ardente sem a ela misturar as convenções de uma virtude equívoca, nem mesmo sob a forma de reivindicação em favor de uma mulher vítima da má fé masculina.* $^{*}$

No romance, torna-se claro, de fato, que o problema de Mariane não é se adequar a uma nova forma de amar, simultane-

\footnotetext{
${ }^{6}$ Em sua recente tradução, Samuel Titan Jr. opta por "comoção": "tão sensível foi a comoção que ele parecia fazer força para se separar de mim e sair ao teu encontro". Essa escolha aponta para o parentesco entre mouvement e émotion, confirmada, aliás, pelo verbete commotion na primeira edição do Dictionnaire de l'Académie: simplesmente "Voy MOUVOIR" (: 216). Cf., para a tradução: Guillerages, Crébillon e Denon. Na alcova: três histórias licenciosas (São Paulo: Companhia das Letras, 2001: 10).
} 
" "Je vous écris pour la der. nière fois, et j'espère vous faire connaître, par la dif. férence des termes et de la manière de cette lettre, que vous m'avez enfin persuadée que vous ne m'aimiez plus, et qu'ainsi je ne dois plus vous aimer" (: 98).

" “Je n'ai bien connu l'excès de mon amour que depuis que j'ai voulu faire tous mes efforts pour m'en guérir" (: 99).

"(: 68).

" "Il me semble que je fais le plus grand tort du monde aux sentiments de mon cœur, de tâcher de vous les faire connaître en les écrivant: que je serais heureuse, si vous en puviez bien juger par la violence des vôtres" (: 79).

amente heróica e sofrida, que notadamente Rousseau defenderá. Seu incômodo crescente até a decepção final, que justifica ser a quinta a última das cartas, demonstra nitidamente que ela luta contra uma ilusão perigosa que a enlevara durante algum tempo, mas que deve ser extinta e, se possível, nunca mais experimentada: "Eu vos escrevo pela última vez, e espero fazerdes conhecer, pela diferença dos termos e da maneira desta carta, que enfim me persuadais que não me amais e que, desse modo, não devo mais amar-vos"*. Se tal enlevamento é fascinante e sedutor tanto para o leitor quanto para a protagonista-narradora, é também desabonador, pois ameaça arrastar a mulher - que, lembre-se, tem papel ativo no Ancien Régime - para longe de uma racionalidade e um equilíbrio cortesãos.

Na verdade, Mariane chega a escrever que só teve acesso a seus transbordamentos amorosos porque lutou com afinco para combatê-los: "Só conheci bem o excesso de meu amor a partir do momento em que quis fazer todos os esforços para dele me curar"*. Portanto, nada de ímpeto de lutar contra os constrangimentos e convenções sociais que atrapalham seu amor - como a protagonista de La princesse de Clèves, Mariane é quem decide pela luta antiamorosa, em prol de uma lucidez socialmente favorecida da mulher que não conhece a posição de vítima.

Se as Portuguesas não contêm nenhuma reivindicação em favor dos direitos do amor ou da mulher, é sem dúvida porque esses direitos são considerados como já adquiridos no mundo de madame de Longueville e de Condé, de Henriette da Inglaterra e de Luís XIV.
Si les Portugaises ne contiennent aucune revendication en faveur des droits de l'amour ou de la femme, c'est sans doute que ces droits sont considérés comme acquis dans le monde de Mme de Longueville et de Condé, de Henriette d'Angleterre et de Louis XIV.

Na verdade, o decoro da protagonista diante dos próprios enlevamentos, que ameaçam sempre transmitir dela um retrato desabonador diante da honnêteté (cuja tradução é algo como "honradez recatada") do gentilhomme que ela ama, é perceptível em várias passagens, como no início da segunda carta: "Parece-me que faço o maior mal do mundo aos sentimentos de meu coração, quando tento trazê-los a vosso conhecimento ao escrevê-los: como eu ficaria feliz se vós pudésseis julgá-los a partir da violência dos vossos"*. Setenta e um anos depois, 
em um célebre romance inglês de 1740, tal decoro feminino será substituído, pela primeira vez, por condenação dos atos do amante e explícita reivindicação de virtude feminina. Trata-se de Pamela, de Samuel Richardson, em que, na mesma tradição do romance epistolar, retomada no século XVII por Lettres portugaises, a problemática íntima e subjetiva se disporá disposta de forma diferente. ${ }^{7}$

A próxima aparição de mouvement no romance de Guillerages indica uma variação de significado importante para nós. No fim da segunda carta, Mariane escreve: "Ah! Não vos constranjais, absolutamente, não quero de vós senão o que viria de vosso movimento, e recuso todos os testemunhos de vosso amor, dos quais vós poderíeis dispensar-vos [...]"** . Mouvement, no caso, contrapõe-se a uma retórica amorosa vazia, da qual o interlocutor amado poderia se dispensar. Percebem-se ecos de sentidos mais arcaicos, ligados à idéia de um dínamo que põe em movimento, na alma ou no nível da moral, impulsos, afecções ou paixões. Em vez da "vontade", outro poderoso dínamo responsável por mover a alma dos homens, trata-se, nesse caso, de um mouvement muito mais perigoso e incontrolável, posto que involuntário. A própria Mariane seria um dos primeiros exemplos de alguém subjugado a tal "movimento", que luta por curar-se. Estamos também às voltas com ecos do significado aristotélico de pathos ou passio, mas em momento mais complexo, já que tardio. Na verdade, como indica Auerbach, a complexidade aristotélica já previa tal amplitude semântica:

Nela mesma, a dialética do aristotelismo já abria ao conceito de $\pi \alpha ́ \theta$ os (pathos) certa possibilidade de ativação, pois, em face do elemento ativo que o afeta, o elemento passivo encontra-se

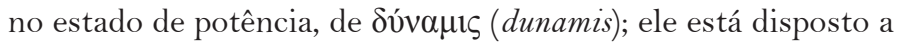

${ }^{7}$ Sobre a subjetividade que se transforma com Pamela, ver Vasconcelos, Sandra G. Dez lições sobre o romance inglês do século XVIII (São Paulo: Boitempo Editorial, 2002: 71-83). Sobre verossimilhança e romance epistolar, bem como sobre deslocamento de perspectiva (no caso, o etnocentrismo atacado por Lettres d'une péruvienne, de 1747, ver: Lajolo, Marisa. "Romance epistolar: o voyeurismo e a sedução dos leitores”, Matraga, n. 14. Rio de Janeiro, 2002: 61-75.

${ }^{8}$ Outra vez, o cotejo com a tradução para o português é esclarecedor. O tradutor optou por: "Ah, não te forces, quero de ti apenas o que vier de moto-próprio...". A solução é engenhosa, mas impede que se cogite uma dinâmica do termo: na frase original, mouvement se contrapõe a "testemunhos de amor não imprescindíveis", ou seja, intencionalmente dissimulados. Mouvement indicaria uma força mais íntima, incontrolável pelo desejo de dissimulação. O problema é que "moto-próprio" dá a idéia exatamente de ato da vontade, interessado - diríamos nós, hoje, consciente. Cf. Guillerages, Crébillon e Denon. Na alcova: três histórias licenciosas. Ob. cit.: 16.
" "Ah! Ne vous contraignez point, je ne veux de vous que ce qui viendra de votre mouvement, et je refuse tous les témoignages de votre amour, dont vous pourriez vous empêcher [...]" (: 82). 
" (Auerbach, Erich. "De la Passio aux passions". Ob. cit: 55).

* (: 55).

" "je veux que tout le monde le sache, je n'en fais point un mystère, et je suis ravie d'avoir fait tout ce que j'ai fait pour vous contre toute sorte de bienséance" (Guillerages. Lettres portugaises. Ob. cit.: 82). sofrer o efeito daquele elemento; sob o efeito do que o afeta, ele é movido ou transformado; ele se põe, portanto, em movimento, e esse movimento é, também ele, qualificado de $\pi \alpha ́ \theta 0 \varsigma^{*}$.

Percebemos, portanto, que, ao tratar de pathos (paixão), Auerbach se depara com o sentido de "movimento", sem, no entanto, deter-se na questão que aqui nos move. Ao apontar para uma postura ativa com base na passividade inicial, como se o objeto passivo fosse afetado por um dínamo vindo de fora que o pusesse em movimento, Auerbach toca em uma semântica que extrapola a Idade Média, considerada por ele o momento em que tal significação surge. A seu ver, aliás, não houve desenvolvimento posterior de tais aspectos medievais de pathos: "Esses pensamentos [...] foram retomados e desenvolvidos na Idade Média, notadamente pelo tomismo, mas sem dúvida se mantiveram sem incidência sobre o uso lingüístico geral”* . Apesar disso, não seria a prosa de ficção local de singularidades e rearranjos culturais inusitados e, como tal, capaz de favorecer a retomada de significados esquecidos pela cultura? Em outras palavras, queremos defender a idéia de que, embora a visão estóica de passio como antítese de ratio (razão) tenha tido futuro mais promissor na cultura ocidental, com conseqüências "mais pesadas”, como escreve Auerbach, não é impossível perceber, na passagem citada de Lettres portugaises, o sentido medieval de passio apontado pelo crítico, ampliando a semântica do termo mouvement em pleno século XVII francês.

Parece-nos, portanto, que o trecho citado do romance remete à concepção de um feixe de impulsos, afecções ou paixões que entram em estado de dinamismo, no caso da protagonista, ou seja, que, a partir de uma passividade inicial, dão lugar ao movimento interno. Tal estado só é possível porque ela reconhece o amor publicamente ou, ao menos, no espaço do convento, onde vive: "quero que todo mundo o saiba, não faço dele de forma nenhuma um mistério, e estou muito feliz de ter feito tudo o que fiz por ti contra todo tipo de decoro"*. Se pensarmos na extrema discrição e na constante sensação de vigia mútua e opressiva de outra protagonista às voltas com seus íntimos mouvements, a do romance La Princesse de Clèves, surgido nove anos depois de Lettres portugaises, teremos acesso a um outro retrato da ousadia necessária à revelação do amor no seio de uma sociedade de corte - mesmo se descontada a situação de Mariane, que, no convento, foge ao regime opressor que grassa na société, mas 
se submete a um outro regime de opressão, no caso, religiosa. Embora uma passagem como a última citada possa confundir mais uma vez o leitor à cata da ancestralidade do amor transbordante romântico, contra todos os “decoros” (bienséances), não podemos nos esquecer de que Mariane deseja nada menos que extinguir o mouvement de que sofre, creditando o próprio fato de tê-lo percebido à vontade de querer acabar com ele, como indicado acima, ou seja, talvez se trate, em Mariane, de uma luta titânica entre vontade e involuntário, uma luta individual e pouco voltada para o socius (ao contrário de Madame de Clèves). Desse modo, é possível aproximar o sentido de mouvement, no texto atribuído a Guillerages, tanto da passio medieval quanto da estóica, pejorativamente contraposta à razão. Não seria este uma síntese entre os dois sentidos, decorrendo daí o sucesso do romance? Assim, se é o elemento externo que põe em movimento a paixão (o impulso) e o indivíduo (Mariane), assim que o percebe, só quer saber de extinguir tal movimento, trata-se da combinatória dos sentidos medieval (o pôr em movimento por um dínamo externo) e estóico (a ratio contra a passio). Este, segundo Auerbach, é o que figura as paixões como “[...] uma inquietude, um estado anárquico de emoção e de agitação que perturba a quietude do sábio. A palavra passio adquire uma significação nitidamente pejorativa; é preciso evitar, tanto quanto possível, ser interiormente atingido e comovido [ému] pela agitação do mundo"*.

$\mathrm{Na}$ terceira carta, por sua vez, lê-se: “agora eu conheço a má-fé de todos os teus movimentos: tu me traíste todas as vezes que me disseste que estavas feliz de estar sozinho comigo; [...] tu perseguiste com frieza o objetivo de me inflamar, não viste minha paixão senão como uma vitória, e teu coração não foi por ela profundamente tocado"*9. A passagem é esclarecedora quanto ao que se mostra exterior à paixão, ativada de fora, mas vivida por Mariane como vinda de seu interior: na verdade, o dínamo, responsável pela inoculação da paixão e, portanto, pela deflagração do movimento (íntimo) da protagonista, nem bem ela nota o perigo em jogo (ao iniciar a luta contra ele), não é interno, ou seja, aquele a quem ela ama só conhece, em
"(Auerbach. "De la Passio aux passions". Ob. cit. : 56).
" "je connais présentement la mauvaise foi de tous vos mouvements: vous m'avez trahie toutes les fois que vous m'avez dit que vous étiez ravi d'être seul avec moi ; [...] vous aviez fait de sens froid un dessein de m'enflammer, vous n'avez regardé ma passion que comme une victoire, et votre cœur n'en a jamais été profondément touché" (Guillerages. Lettres portugaises. Ob. cit.: 85 )

\footnotetext{
${ }^{9} \mathrm{Na}$ tradução brasileira, lê-se "gestos", em vez de "movimentos”, o que demonstra desconhecimento do sentido da palavra à época: "Sim, sei agora da má-fé de todos os seus gestos”. A opção exclui a idéia de interioridade. Cf. Guillerages, Crébillon e Denon. Na alcova: três histórias licenciosas. Ob. cit.: 18.
} 
" (Perrin, Jean-François e Stewart, Philip. (org.). Du genre libertin au XVIIlè siè cle. Paris: Desjonquères, 2004; Delon, Michel. Le savoir-vivre libertin. Paris Hachette, 2000; Goldzink, Jean. Le vice en bas de soie. Paris: José Corti, 2001).

" "Adieu, je n'ose vous donner mille noms de tendresse, $n$ m'abandonner sans contrain te à tous mes mouvements" (Guillerages. Lettres portugaises. Ob. cit.: 96).

" "qu'est-ce que vous vouliez faire de tous mes empor. tements, qui ne pouvaient vous être que très impor. tuns?" (: 91).

" “j'écris plus pour moi que pour vous, je ne cherche qu'à me soulager" (: 97).

" "je crois même que je ne vous écrirai plus; suis-je obligée de vous rendre un compte exact de tous mes divers mouvements?" (: 106). relação a ela, um tipo de movimento que nada tem a ver com amor: trata-se de um galante, no sentido seiscentista, ou libertino, no sentido que a palavra assume no século XVIII*. Fria e indiferentemente, crê poder conquistá-la apenas pelo prazer da conquista, sem nenhum dínamo amoroso interno (sem sofrer ou ser sofrido por nenhuma paixão).

Na quarta carta, o mouvement retorna: "Adeus, eu não ouso te dar mil nomes de ternura, nem me abandonar sem freio a todos os meus movimentos ${ }^{\prime *}{ }^{*}$. Depois da constatação da libertinagem e da falta de paixão irrecorrível por parte do gentilhomme francês, não se trata mais de tais movimentos calculados, e sem deflagração íntima, do amante que não a ama, como era o caso na carta anterior, mas de seus próprios movimentos, pelos quais, mais uma vez, Mariane se considera a única responsável ("o que querias fazer de todos os meus enlevamentos, que só podiam ser-te bastante inoportunos!")*.

A última frase do romance inclui, outra vez, o termo mouvement, concluindo a saga individual e isolada da freira portuguesa às voltas com a própria cura: "escrevo mais para mim que para vós, procuro apenas me aliviar"*, escreve Mariane ainda na quarta carta, de modo a retornar a seus próprios movimentos internos, que, afinal, nada têm mais a ver com o gentilhomme français: "creio mesmo que não vos escreverei mais; sou obrigada a vos relatar com exatidão todos os meus diversos movimentos?"* ${ }^{11}$. É nítido que, nessa frase final, mouvements se refere à própria oscilação emocional da protagonista, que compõe a matéria de que são feitas suas cartas e que, daí em diante, será para sempre inacessível ao ex-amado. Se ele fôra o deflagrador dos mouvements, no sentido medieval apontado por Auerbach, e se Mariane lutara estoicamente contra tal dinamismo, tendo acesso a ele apenas por querer combatê-lo ${ }^{12}$, agora tais mouve-

${ }^{10} \mathrm{Na}$ tradução para o Brasil: “em a abandonar-me sem peias a meus ímpetos”. Percebe-se a aproximação do significado de impulso, afecção, próximo ao seiscentista francês. Cf. Guillerages, Crébillon e Denon. Na alcova: três histórias licenciosas. Ob. cit.: 30.

${ }^{11}$ Depois de traduzir mouvement por "ímpeto", o tradutor brasileiro escolhe um termo que terá destino feliz na literatura dos séculos seguintes: "sou acaso obrigada a te prestar contas exatas de todos os meus sentimentos?” A seqüência dos termos escolhidos para a tradução não deixa de revelar certa evolução semântica sub-reptícia: comoção, moto-próprio, gestos, ímpetos e sentimentos. Cf. Guillerages, Crébillon e Denon. Na alcova: três histórias licenciosas. Ob. cit.: 39.

${ }^{12}$ Tal aparente paradoxo, segundo o qual ela só tem acesso à sua própria inquietude porque quer combater o que sente, faz pensar na semântica de um amor a princípio sub-reptício, que não se deixa flagrar de imediato e ameaça atuar sem ser notado. É o 
ments são finalmente apropriados pela própria Mariane: ela não mais os partilhará por meio das cartas, tendo se tornado uma espécie de mestre de seu próprio destino emocional.

\section{Nascimento da "émotion" a partir do "mouvement"}

Por fim, destaquemos que na primeira edição do Dictionnaire de l'Académie, de 1694, tanto os termos "émouvoir" e "émouvante" quanto o próprio termo "émotion” não merecem verbetes próprios: são remetidos, respectivamente, para os verbetes de "mouvante" e, o que é surpreendente no caso do substantivo “émotion”, de "mouvoir", já citado por nós, acima ${ }^{13}$. Isso dá a medida do pouco uso, na época, do prefixo "e" nas variantes de "mouvoir". Tal fato prova também que a idéia de um movimento interno era dominante, quando se tratava de alterações íntimas: não havia ainda um sentido consagrado de émotion no sentido de "reação afetiva estabilizada" ou "estado afetivo estável", reinando sozinho o sentido de "variação”, muito próximo ao de "movimento" 14 .

Em 1740, em sua terceira edição, 16 anos depois da primeira, o Dictionnaire de l'Académie traz a palavra "émotion" com verbete próprio. Seu campo semântico, agora, inclui os sentidos de “alteração" e "movimento", bem como do hoje arcaico "humores", no sentido médico herdado da Antigüidade: "Alteração, movimento excitado nos humores, no espírito, na alma”* . O sentido médico se torna ainda mais claro apóa a leitura de alguns exemplos que integram o verbete, francamente datados para um leitor contemporâneo: "Tenho medo de estar com febre, senti alguma emoção. Não há mais febre, mas vejo nele ainda alguma emoção […]. Ele andou demais, isso lhe trouxe, lhe causou emoção"*. Por fim, ainda na terceira edição, o verbete "émouvoir" traz: "Pôr em movimento, fazer se mover. Trata-se,

que se observa também em La Princesse de Clèves. Em uma rápida comparação, todavia, poderíamos dizer que madame de Clèves apresenta um comportamento mais cristão e menos estóico que Mariane (sempre no sentido de Auerbach): ela cora ao perceber o nível de intensidade de seu amor, bem como por tê-lo tornado nítido a seu amado, o duque de Nemours, mas, em vez de combater verbalmente tal excesso, prefere sofrer, calada, a força de tal emoção-movimento em um combate íntimo, retirando-se, em seguida, dos salons e do monde. Mais discreta ainda que seu marido, que antes de morrer (de amor) esbraveja contra a traição, madame de Clèves tem uma última conversa com o duque, e se vale do próprio combate íntimo e da fraqueza advinda da doença que se segue àquele combate para encontrar uma saída: o afastamento em relação ao monde.

${ }^{13} \mathrm{O}$ mesmo ocorre com commotion. Ver nota 6.

${ }^{14}$ Tais sentidos mais modernos são claros principalmente no campo da psicologia.
" "Altération, mouvement ex cité dans les humeurs, dans les esprits, dans l'ame" (Dictionnaire de l'Académie françoise, Tome Premier. Troisième édition. Paris: Jean-Baptiste Coignard 1740: 568)

\footnotetext{
" “J'ai peur d'avoir la fièvre, j'ai senti quelque émotion. II n'a plus la fièvre, mais je lui trouve enconre quelque émo tion [...]. II a trop marché, cela lui a donné, lui a causé de l'émotion" ( : 568).
} 
" "Mettre en mouvement, faire mouvoir. II ne se dit guére que des parties les plus subtiles \& plus mobi. les d'un corps, comme sont les humeurs, les vapeurs, les esprits" (: 569).

" "Terme de Médecine. Ébranlement violent au de dans du corps, causé par une chute, ou par quelque coup. II y a à craindre que ce coup, que cette chute n'ait fait commotion au cerveau. II tomba de fort haut, ce qui lui causa une commotion générale dans tout le corps" (: 342).

* (Guillerages. Lettres portugaises. Ob. cit.: 76). tão-somente, das partes mais sutis e mais móveis de um corpo, como são os humores, os vapores, o espírito"*15.

O termo "commotion" surge na edição de 1740 exclusivamente com o significado médico: "Termo da Medicina. Abalo violento no corpo, causado por uma queda, ou por qualquer golpe. É de temer que esse golpe, que essa queda tenha causado comoção no cérebro. Ele caiu de muito alto, o que lhe causou uma comoção geral em todo seu corpo"** A idéia de uma interioridade corporal individual ganha ares literais, em um momento mais cientificista: na topografia do corpo, o local próprio dos movimentos é o interior.

\section{Conclusão}

Com a frase final de Lettres portugaises, “je crois même que je ne vous écrirai plus; suis-je obligée de vous rendre un compte exact de tous mes divers mouvements?"*, chegamos ao último momento da saga semântica aqui descrita, paralela à saga íntima de Mariane: a da oscilação de sentido do termo mouvement. Frédéric Deloffre defende que o romance nada tem de monocórdio, apresentando uma seqüência reconhecível: "há em Mariane uma evolução radical dos sentimentos que cria uma tensão dramática bastante diferente daquela lamentação imóvel à qual se pretende reduzir a obra"* Como vimos em nosso estudo, tal seqüência evolutiva pode ser flagrada, de forma bastante clara, pela análise do uso do termo mouvement no romance, termo, aliás, que surge exatamente uma vez a cada carta. Como vimos também, tal termo aparece envolvido sob o signo de significados cuja origem remonta tanto a Aristóteles e ao estoicismo quanto à Idade Média. Tais significados circunscrevem a palavra com uma semântica do enlevamento sofrido como uma espécie de doença (sentido aristotélico da palavra), que fora causada por um dínamo externo (sentido medieval) e que quer extinguir-se por vontade própria (sentido estóico). A força de Lettres portugaises talvez venha dessa tensão entre três tradições de representação da vida da "alma”.

Tal decodificação dos mouvements internos e externos à protagonista-narradora nos leva a uma lógica da inoculação, do transbordamento e da contenção: esses três tempos podem

\footnotetext{
${ }^{15}$ Quanto à última palavra da citação, esprits, sabe-se da dificuldade de traduzi-la para o português, dada a especificidade cultural do significado do termo. Nesse caso, a opção pelo singular nos pareceu a mais coerente.
} 
ser notados na seqüência do uso do termo. Recapitulemos. Na primeira carta, trata-se dos movimentos de seu coração, percebidos pela primeira vez. Na segunda, Mariane clama por um mouvement interno de seu amante, com um dínamo - dir-se-ia autodeflagrador. A terceira carta é a da constatação e do ressentimento diante da percepção de que os mouvements do amado não possuem tal dínamo ou eixo interno: são meros exercícios de galanteador. Na quarta carta, depois de um "Adieu”, ela se nega a abandonar-se aos seus próprios movimentos internos, inexistentes no outro. Por fim, a protagonista nega ao ex-amado inclusive a narrativa de tais movimentos; dali em diante, suspenderá a própria escrita para se abandonar a novos movimentos, que nada mais terão a ver com o ex-amado. O movimento de progressiva autonomização se terá completado.

Se a palavra émotion já aparece na primeira citação que fizemos do romance - “je fus si accablée de toutes ces émotions violentes, que je demeurai plus de trois heures abandonnée de tous mes sens" -, aprendemos que o sentido moderno, dado hoje como banal, não era muito comum por volta de 1669, quando Lettres portugaises foi publicado. Palavra criada a partir de mouvoir havia relativamente pouco tempo, émotion, no trecho citado, era apenas um sinônimo menos utilizado para mouvement. Este, por sua vez, ajudou a forjar uma semântica do dinamismo interno, como que ajudando a colonizar o "dentro”, também apelidado de "espírito”, “alma” ou, para sermos contemporâneos, subjetividade. 


\section{André Luiz Barros}

Aluno do Programa de Pós-Graduação da Universidade do Estado do Rio de Janeiro. Bolsista Nota 10 - Faperj.

Palavras-chave

romance seiscentista francês semântica

constituição da intimidade (subjetividade).
Key words

French novel of the XVII century

semantics

constitution of intimacy (subjectivity)

\section{Mots-clé}

Roman français du XVlesiècle Sémantique

constitution de l'intimité (subjectivité)

Recebido em 11/04/2006 09/06/2006

\section{Resumo}

Investigação sobre o uso da palavra mouvement (movimento) no romance Lettres portugaises (1669). A análise das incidências do termo (uma vez em cada uma das cinco cartas) ajuda a flagrar um momento da formação de uma nova concepção da subjetividade no Ocidente. Sentidos de mouvement são cotejados aos significados aristotélico, estóico e medieval de "paixão" (pathos) (Auerbach). Verbetes de mouvement e émotion de duas edições do Dicctionnaire de l'Académie françoise (1694-1740) ajudam a alargar a compreensão da semântica de mouvement - e de émotion, como sua derivada - no romance setecentista, de modo a esclarecer modos de constituição da narrativa das variações íntimas em nossa cultura.

\section{Abstract}

The text is a search about the use of the word mouvement (in French) in the novel Lettres portugaises (1669). The analysis of the incidences of the word (one time in each one of the five letters) helps us to focus in a determined phase of the development of a new conception of the subjectivity in Western culture. Some senses of mouvement are compared to the Aristotelian, the Stoic and Medieval senses of "passion" (pathos) (Auerbach). Entries of mouvement and émotion in two editions of the Dicctionnaire de l'Académie françoise (1694-1740) helps us to broaden the comprehension of the semantics of mouvement-and émotion, as one of its derivatives - in the cited novel as to clarify the constitution of the narrative of the variations of intimacy in our culture.

\section{Résumé}

Investigation sur l'emploi du mot mouvement dans le roman Lettres portugaises (1669). L'analyse de l'usage du mot (une fois dans chacune des cinq lettres) aide à décrire un moment de la formation d'une nouvelle conception de la subjectivité en Occident. Les sens de mouvement sont comparés aux significations aristotélicienne, stoïque et médiévale de passion (pathos) (Auerbach). Les articles de mouvement et émotion dans deux éditions du Dictionnaire de l'Académie françoise (1694-1740) aident à élargir la compréhension de la sémantique de mouvement-et d'émotion, qui en dérive - dans le roman du XVIIe siècle, pour éclaircir les moyens de constitution du récit des variations intimes dans notre culture. 